\title{
TO STUDY SERUM ELECTROLYTE PROFILE IN 1 MONTH-5 YEARS CHILDREN WITH DEHYDRATION ADMITTED TO KIMSDU HOSPITAL, KARAD
}

\author{
Jaiom Dagar1, Prashant Shah², Allapa Mallapa Koppad³, Siddharth Singh ${ }^{4}$ \\ ${ }_{1}^{1}$ Resident, Department of Paediatrics, Krishna Institute of Medical Sciences Deemed University. \\ ${ }^{2}$ Assistant Professor, Department of Paediatrics, Krishna Institute of Medical Sciences Deemed University. \\ ${ }^{3}$ Professor, Department of Paediatrics, Krishna Institute of Medical Sciences Deemed University. \\ ${ }^{4}$ Resident, Department of Paediatrics, Krishna Institute of Medical Sciences Deemed University.
}

\section{BACKGROUND}

ABSTRACT

Acute gastroenteritis is an extremely common illness among infants and children worldwide. In developing countries, diarrhoea is a common cause of mortality among children below 5 years age, with an estimated 2 million deaths each year. Diarrhoea is defined as the passage of three or more loose or watery stools per day (or more frequent passage of stools than normal for the individual). Frequent passage of formed stools is not diarrhoea, nor is the passing of "pasty" stools by breastfed young infants. [1] The clinical manifestations of acute gastroenteritis can include diarrhoea, vomiting, fever, anorexia, and abdominal cramps. Vomiting followed by diarrhoea may be the initial presentation in children or vice versa.

Aims and Objectives of this study are

1. To study serum electrolytes changes in 01 month to 5 years children with diarrhoeal diseases.

2. To the study the factors which influence the electrolyte balance in these children.
a) Degree of dehydration.
b) Degree of PEM.
c) Type of feeding.
d) Type of treatment ORS/IV fluids.
e) Immediate outcome.

\section{MATERIALS AND METHODS}

Study Design- This was a prospective interventional study.

Study Period- 24 months (August, 2013 to July, 2015).

Sample Size- All patients admitted to Paediatrics Ward of Krishna Hospital with complaints of loose stools and vomiting.

\section{RESULTS}

A total of 434 children in the age group of 01 month to 5 years were admitted to Paediatric ward of Krishna hospital with features of acute gastroenteritis during study period. The cases of gastroenteritis are significantly more in the males in our study. In our study, hyperchloraemia was the commonest electrolyte abnormality (42.40\%), followed by hyperkalemia (26.40\%) and hypernatremia (20.60\%). Hypokalaemia was seen in $20(64.5 \%)$ of SAM patients and hyponatraemia was seen in $9(29 \%)$ of SAM patients. None of the 434 children died during the study period; 411(94.7\%) were discharged from the hospital, and 23 (5.3\%) left the hospital against medical advice.

\section{CONCLUSION}

The findings of our study reiterate the need for effective oral rehydration therapy for the prevention of the serious consequences of diarrhoea. The mild nature of disease can be easily \& effectively controlled at house-hold level with Oral Rehydration Solution or home based fluids.

\section{KEYWORDS}

Acute Diarrhoea, Gastroenteritis, Children, Hydration, Child Nutrition, WHO.

HOW TO CITE THIS ARTICLE: Dagar J, Shah P, Koppad AM, et al. To study serum electrolyte profile in 1 month- 5 years children with dehydration admitted to KIMSDU Hospital, Karad. J. Evolution Med. Dent. Sci. 2016;5(99):7263-7266, D0I: 10. 14260/jemds/2016/1643

Financial or Other, Competing Interest: None.

Submission 07-11-2016, Peer Review 01-12-2016,

Acceptance 07-12-2016, Published 12-12-2016.

Corresponding Author:

Dr. Jaiom Dagar,

IHR Hostel,

KIMSDU, Karad Taluka

Satara-124507,

Maharashtra.

E-mail: jai.dagar05@gmail.com

DOI: $10.14260 /$ jemds/2016/1643

\section{BACKGROUND}

Acute gastroenteritis is one of the most common childhood diseases, especially in developing countries. There are three clinical classifications of diarrhoeal conditions: Acute diarrhoea, lasting several hours or days; acute bloody diarrhoea or dysentery; persistent diarrhoea, lasting 14 days or longer. Vomiting followed by diarrhoea may be the initial presentation in children, or vice versa.[1] A complete history and physical examination always must be performed. The physical examination should focus on identifying signs of dehydration such as level of alertness, presence of sunken 
eyes, dry mucous membranes, and skin turgor.[2] The treatment of gastroenteritis in children focuses on preventing dehydration.

A child with minimal or no dehydration should be encouraged to continue his or her usual diet plus adequate fluids. Many studies have shown that a child's regular diet reduces the duration of diarrhoea. Probiotics can be used to shorten the course of diarrhoea. Good hand washing reduces the incidence of acute gastroenteritis, but not rotavirus. Early oral rehydration therapy using an oral rehydration solution (ORS), before the child becomes more severely dehydrated, is important and can be done at home.[3] Clear liquids, such as water, sodas, chicken broth, and apple juice, should not replace an ORS because they are hyperosmolar and do not adequately replace potassium, bicarbonate, and sodium. Criteria for hospital admission include caregivers who are unable to adequately administer an ORS at home, intractable vomiting, poor ORS intake by mouth or nasogastric tube, profuse diarrhoea, unusual irritability or drowsiness, or no symptom improvement after 24 hours of ORS administration at home.[3] An ORS is composed of sodium, dextrose, and bicarbonate in a ratio that does not overwhelm the hyperactive bowels with a hyperosmolar solution, but that is strong enough to replace the electrolyte loss. ${ }^{[4]}$ Annually 2.5 million deaths are estimated to occur due to enteric infections, greatly impacting children below five years of age.[5]

\section{MATERIALS AND METHODS}

\section{Aims and Objectives}

1. To study serum electrolytes changes in children of age 1 month to 5 years with diarrhoeal diseases.

2. To study the factors which influence the electrolyte balance in these children.
a) Degree of dehydration.
b) Degree of PEM.
c) Type of feeding.
d) Type of treatment ORS/IV fluids.
e) Immediate outcome.

\section{Study Design}

This was a prospective interventional study.

\section{Study Period}

24 months (August 2013 to July 2015).

\section{Sample Size}

All patients admitted to Paediatrics Ward of Krishna Hospital with complaints of loose stools and vomiting.

\section{Inclusion Criteria}

All children in age group of 1 month to 5 years admitted to Paediatric Ward with diagnosis of acute gastroenteritis.

\section{Exclusion Criteria}

Any children admitted with diagnosis other than acute gastroenteritis in age group of 1 month to 5 years. Neonates and children above 5 years were excluded from study.

\section{METHODOLOGY}

This was a prospective interventional study and was conducted in Paediatric Ward of Krishna Hospital and Research Centre, Karad. The trial was approved by ethical committee of Krishna Institute of Medical Sciences before it was conducted. Written informed consent was obtained from the parents of children prior to the enrolment of subjects in the study. Blood and stool samples were sent for investigation.

\section{Outcome Measures and Followup}

Outcome was measured in terms of various anthropometry parameters and improvement in knowledge of parents of children involved in our study.

\section{Statistical Analysis}

The data related to acute gastroenteritis was collected such as age, gender, electrolyte imbalance and degree of dehydration. The categorical data is presented as frequencies and percentages.

\section{RESULTS}

A total of 434 children in the age group of 01 month to 5 years were admitted to Paediatric Ward of Krishna Hospital with features of acute gastroenteritis during study period. The admissions due to acute gastroenteritis accounted for $27.40 \%$ of the total 1584 admissions during study period in Paediatric Ward. The month wise number of gastroenteritis cases was in the range of 11 to 36 . Out of the total 434 cases of gastroenteritis, males were $54.40 \%$ and females were $45.60 \%$. The cases of gastroenteritis are significantly more in the males in our study.

\begin{tabular}{|c|c|c|}
\hline & Number (N = 434) & Percentage \\
\hline Male & 236 & $54.40 \%$ \\
\hline Female & 198 & $45.60 \%$ \\
\hline \multicolumn{2}{|c|}{ Table 1. Shows the Distribution of Acute Gastroenteritis } \\
Patients According to their Gender \\
\hline
\end{tabular}

According to age, 185 (42.6\%) were between 1 month and 12 months, 167 (38.4\%) were between 13 months and 36 months and 82 (19\%) were between 37 months and 60 months.

\begin{tabular}{|c|c|c|}
\hline & Number (N = 434) & Percentage \\
\hline $1-12$ Months & 185 & $42.6 \%$ \\
\hline $13-36$ Months & 167 & $38.4 \%$ \\
\hline 37 - 60 Months & 82 & $19 \%$ \\
\hline Table 2. Shows the Distribution of Acute Gastroenteritis \\
Patients According to their \\
Age \\
\hline
\end{tabular}

In our study, 12 children with diarrhoea had no dehydration but admitted for parent's apprehension, 77.4\% patients had some dehydration and $19.8 \%$ had severe dehydration.

\begin{tabular}{|c|c|c|}
\hline & Number (N = 434) & Percentage \\
\hline No dehydration & 12 & $2.8 \%$ \\
\hline Some dehydration & 336 & $77.4 \%$ \\
\hline Severe dehydration & 86 & $19.8 \%$ \\
\hline Table 3. Shows the Distribution of Acute Gastroenteritis \\
Patients with Dehydration \\
\hline \multicolumn{2}{|c|}{} \\
\hline
\end{tabular}

It was noted in our analysis that $31(7.1 \%)$ of our patients had severe acute malnutrition and was treated for SAM (severe acute malnutrition) also. Hypokalaemia was seen in 20 
(64.5\%) of SAM patients and hyponatraemia was seen in 9 (29 $\%)$ of SAM patients. In our study, hyperchloraemia was the commonest electrolyte abnormality (42.40\%), followed by hyperkalaemia (26.40\%) and hypernatraemia (20.60\%). The abnormal serum creatinine level was reported in $51(11.7 \%)$ cases.

\begin{tabular}{|c|c|c|c|}
\hline Electrolytes & Low & Normal & High \\
\hline $\begin{array}{c}\text { Sodium } \\
(\mathrm{N}=434)\end{array}$ & $09.10 \%$ & $70.30 \%$ & $20.60 \%$ \\
\hline $\begin{array}{c}\text { Potassium } \\
(\mathrm{N}=434)\end{array}$ & $07.20 \%$ & $67.40 \%$ & $26.40 \%$ \\
\hline $\begin{array}{c}\text { Chloride } \\
\text { (N=434) }\end{array}$ & $08.60 \%$ & $49.10 \%$ & $42.40 \%$ \\
\hline $\begin{array}{c}\text { Table 4. Shows the Distribution of Acute Gastroenteritis } \\
\text { Patients According to Electrolyte Profile }\end{array}$ \\
\hline
\end{tabular}

We found that $72.6 \%$ of mothers continued to feed during diarrhoea in less than 2 years age group. Regarding the treatment used for acute gastroenteritis in our hospital, 72 (16.6\%) cases were treated with only WHO ORS, 362 (83.4\%) cases were treated with both WHO ORS and intravenous fluids and $7.32 \%$ were given antibiotics. On observation, we found that majority of mothers of the children were in the age group 21-25 years (61.4\%). About $59.6 \%$ of the mothers were educated till middle class school. In our study, majority of patients belonged to joint family $298(68.7 \%)$ and upper lower socio-economic class 184 (42.4\%). None of the 434 children died during the study period; $411(94.7 \%)$ were discharged from the hospital, and 23 (5.3\%) left the hospital against medical advice.

\section{DISCUSSION}

The high incidence of diarrhoeal disorders requiring patient hospitalisation confirms the immense importance of acute gastroenteritis with regard to public health. The prevalence of viral aetiology in India has been found to vary in the range 5$71 \%$ in hospitalised children aged less than 5 years with acute gastroenteritis. Acute gastrointestinal illnesses are amongst the most common diseases in developing countries ranging from no to severe dehydrating illness that can lead to mortality within hours. In our study, the admissions due to acute gastroenteritis accounted for $27.40 \%$ of the total 1584 admissions during study period in Paediatric Ward. Although acute gastroenteritis is a common illness in all seasons, it definitely shows change in the number of cases at different times of the year. In our study, the month wise number of gastroenteritis cases was in the range of 11 to 36 . Out of the total 434 cases of gastroenteritis, males were $54.40 \%$ and females were $45.60 \%$. The cases of gastroenteritis were significantly more in the males in our study. In a study by Alimelu et al, $53.3 \%$ were male and $46.6 \%$ were female children[6]; however, there was no gender difference in study by Gupta et al.[7] In our study, hyperchloraemia was the commonest electrolyte abnormality (42.40\%), followed by hyperkalaemia (26.40\%) and hypernatraemia (20.60\%). The abnormal serum creatinine level was reported in $51(11.7 \%)$ cases. Disorders of sodium levels among acute gastroenteritis cases constitute a medical emergency requiring a prompt and adequate diagnosis and management.[8] Different studies have shown different prevalence of hyponatraemia and hypernatraemia among children with dehydration. According to a study by Chouchane et al., hypernatraemia was present in
$11.51 \%$ cases of all kinds of dehydration.[9] In severe malnutrition, significant risk factor for fatal diarrhoea includes hyponatraemia, hypokalaemia and metabolic acidosis.[10] It was noted in our analysis that $31(7.1 \%)$ of our patients had severe acute malnutrition and was treated for SAM (severe acute malnutrition) also.

Hypokalaemia was seen in $20(64.5 \%)$ of SAM patients and hyponatraemia was seen in 9 (29\%) of SAM patients. In a study by Rehana et al, $37 \%$ children with acute diarrhoea were found to be hypokalaemic.[11] It is strongly recommended in WHO guidelines that there is a need to maintain educational campaigns for priority use of ORS, so that new mothers can be educated about its use.[12] None of the 434 children died during the study period; 411(94.7\%) were discharged from the hospital, and 23 (5.3\%) left the hospital against medical advice. The findings in our study also reiterate the need for effective oral rehydration therapy for prevention of serious consequences of diarrhoea.

\section{CONCLUSIONS}

The findings of our study reiterate the need for effective oral rehydration therapy for the prevention of the serious consequences of diarrhoea. Many studies have been conducted in the past to find out the prevalence of different electrolyte disorders among children. Due importance should also be given to the personal hygiene and hand washing practices of family members. This disease, if mild, can be easily and effectively controlled at house-hold level with Oral Rehydration Solution or home based fluids. Only if the gastroenteritis is severe leading to dehydration, then the patient may be taken to the hospital.

\section{REFERENCES}

1. Elliott EJ. Acute gastroenteritis in children. BMJ 2007;334(7583):35-40.

2. World Health Organization. The treatment of diarrhea: a manual for physicians and other senior health workers. Geneva, Switzerland: World Health Organization 2005.

3. King CK, Glass R, Bresee JS, et al. Managing acute gastroenteritis among children: oral rehydration, maintenance, and nutritional therapy. MMWR Recomm Rep 2003;52(RR-16):1-16.

4. Atherly-John YC, Cunningham SJ, Crain EF. A randomized trial of oral vs intravenous rehydration in a pediatric emergency department. Arch Pediatr Adolesc Med 2002;156(12):1240-3.

5. Girard MP, Steele D, Chaignat CL, et al. A review of vaccine research and development: human enteric infections. Vaccine 2006;24(15):2732-50.

6. Alimelu M, Mohan RM, Tuladi V, et al. Prevalence of Noro virus and epidemiology of acute gastroenteritis in children. IAIM 2016;3(6):157-63.

7. Gupta N, Jain SK, Ratnesh, et al. An evaluation of diarrhoeal diseases $\&$ acute respiratory infections control programmes in a Delhi slum. Indian J Paediatrics 2007;74(5):471-6.

8. Petzold A. Disorders of plasma sodium. N Engl J Med 2015;372(13):1267.

9. Chouchane $\mathrm{S}$, Fehri $\mathrm{H}$, Chouchane $\mathrm{C}$, et al. Hypernatremic dehydration in children: retrospective study of 105 cases. Arch Pediatr 2005;12(12):1697-702. 
10. Uysal G, Sokmen A, Vidinlisan S. Clinical risk factors for fatal diarrhea in hospitalized children. Ind J Paedtr 2000;67(5):329-33.

11. Majeed R, Shamsi AH, Rajar U. Clinical manifestation of hypokalemia. J Liaquat Univ Med Health Science 2006;2:50-3.
12. The United Nations Children's Fund (UNICEF)/World Health Organization (WHO). Diarrhea: why children are still dying and what can be done. Geneva 2009. 